\title{
ENSINO DE HISTÓRIA, MEMÓRIA E HISTÓRIA LOCAL
}

\author{
Carlos Henrique Farias de Barros ${ }^{1}$
}

\section{RESUMO}

Este artigo dará continuidade ao projeto de produção científica sobre o ensino de história e sua valorização da memória para a compreensão da história local. A escolha desse tema está baseada em um trabalho sobre Memória e história local elaborado durante a disciplina "História Regional". Para isso irá utilizar a contribuição de autores preocupados com uma maior compreensão sobre a importância do ensino da história local e o resgate de sua identidade histórica e social. A relevância deste trabalho está na compreensão do desenvolvimento de metodologias que favoreçam um ensino de História comprometida com a inserção da história local em sala de aula, valorizando o cotidiano dos alunos.

Palavras-Chave: Cotidiano. Ensino. História. Localidade. Memória.

\section{ABSTRACT}

This article will give continuity the project of scientific literature on the teaching of history and memory enhancement to the understanding of location history. This subject was chosen based on a paper on memory and location history prepared during the course place history. It will use the contribution of authors concerned with a greater understanding about the importance of the teaching of location history and recovery of its historic and societal identity. This work is important to help understand the development of methodologies that favour the teaching of history committed to the inclusion of location history in the classroom, enhancing the daily lives of students.

Keywords: Daily Life. Education. History. Location. Memory.

\footnotetext{
${ }^{1}$ Licenciado em História pela Universidade Salgado de Oliveira (UNIVERSO-RECIFE) Avenida Ministro Marcos Freire, 2301 - Casa Caiada - Olinda-CEP: 53130540 e-mail: historia 2007@hotmail.com
} 


\section{INTRODUÇÃO}

O diálogo entre o ensino de História e o conhecimento científico redimensiona a importância social da área na formação do estudante, sinalizando e fundamentando a possibilidade de estudo e atividade que valorizem a atitude intelectual do aluno no desenvolvimento e envolvimento em trabalhos que favoreçam sua autonomia para aprender.

Nesse contexto, o estudo histórico desempenha um papel importante, na medida em que contempla pesquisa e reflexão da relação construída socialmente e da relação estabelecida entre indivíduo, grupo e o mundo social. Nesse sentido, o ensino de História poderá fazer escolha pedagógica capaz de possibilitar ao aluno refletir sobre seus valores e suas práticas cotidianas e relacioná-los com a problemática histórica inerente ao seu grupo de convívio, à sua localidade, à sua região e à sociedade nacional e mundial.

A construção de noções modifica a maneira como o aluno compreende os elementos do mundo e as relações que esses elementos estabelecem entre si, na medida em que o ensino de História Ihe possibilita construir noções, proporcionando mudanças no seu modo de entender a si mesmo, entender os outros, as relações sociais e a própria História.

Tem sido comum em propostas curriculares e em algumas produções didáticas introduzir a "História do Cotidiano", opção esta que não é recente. A associação entre cotidiano e história de vida dos alunos possibilita contextualizar essa vivência individual a uma história coletiva.

Os autores que se ocupam da História do Cotidiano, mesmo com posturas diversas em seus fundamentos teóricos, buscam recuperar as relações mais complexas entre os diversos grupos socais, estabelecendo conexões entre conflitos diários que se inserem em uma forma de política contestatória e identificar as lutas de resistência a mudanças, o apego a tradições.

É importante destacar que os Parâmetros Curriculares Nacionais de História, demonstram alternativas que favorecem a compreensão dos alunos em relação ao estudo da memória na construção do conhecimento histórico. 
Entre os conceitos presentes no PCN em relação ao ensino de História, destaca-se a importância da construção da identidade individual e social, conceito este fundamental, já que a identidade e a memória têm uma estreita relação, conforme os estudos de M. Pollak.

O estudo sobre a memória se universalizou no momento em que, como nunca, o passado está distante do presente, quando as pessoas não mais identificam sua herança pela perda dos antigos padrões de relacionamento social e a desintegração dos antigos laços entre as gerações.

Para Gaddis (2003), "o estabelecimento da identidade requer o reconhecimento de nossa relativa insignificância no grande esquema das coisas". Esse seria, no seu entender, um dos significados da maturidade nas relações humanas e mais, do próprio valor do uso da consciência histórica.

A construção de identidades pessoais e sociais está relacionada à memória, já que tanto no plano individual quanto no coletivo ela permite que cada geração estabeleça vínculos com as gerações anteriores. Os indivíduos, assim como as sociedades, procuram preservar o passado como um guia que serve de orientação para enfrentar as incertezas do presente e do futuro.

O ensino de história local apresenta-se como um ponto de partida para a aprendizagem histórica, pela possibilidade de trabalhar com a realidade mais próxima das relações sociais que se estabelecem entre educador / educando / sociedade e o meio em que vivem e atuam.

Nessa perspectiva, o ensino-aprendizagem da História Local configura-se como um espaço-tempo de reflexão crítica acerca da realidade social e, sobretudo, referência para o processo de construção das identidades destes sujeitos e de seus grupos de pertença.

O ensino de História Local ganha significado e importância no ensino fundamental, exatamente pela possibilidade de introduzir a formação de um raciocínio de história que contemple não só indivíduo, mas a coletividade, apresentado as relações sociais que ali se estabelecem na realidade mais próxima.

A História Local possibilita a compreensão do entorno do aluno, identificando passado e presente nos vários espaços de convivência. Essa temática permite que o professor parta das histórias individuais e dos grupos, inserindo o aluno em contextos mais amplos. 
Com a abordagem da História Local os alunos passam gradativamente a observar e perceber o significado de outras matérias construídas no passado; a compreender que as realidades históricas de determinada localidade e de seus habitantes no tempo não se dão isoladas do mundo, mas como parte do processo histórico em que populações locais constroem suas identidades culturais e sociais; que estas identidades são diversas, mas todas merecem respeito.

\section{AS BASES LEGAIS QUE FUNDAMENTAM O ENSINO DE HISTÓRIA}

"Os objetivos concretizam as intenções educativas em termos de capacidades que devem ser desenvolvidas pelos alunos ao longo da escolaridade".

(PCN, 1997)

Os Parâmetros Curriculares Nacionais (PCN) para a História dividem-se em duas partes.

Compondo a primeira parte, temos características, princípios, conceitos e algumas concepções curriculares para o ensino de história, além de objetivos gerais, critérios de seleção e organização de conteúdos por área.

$\mathrm{Na}$ segunda parte estão presentes propostas de ensino e aprendizagem para o primeiro e segundo segmentos do ensino fundamental que são divididos em quatro ciclos com objetivos, critérios de avaliação e orientações didáticas para a prática da pesquisa escolar, para o uso de variados materiais didáticos e documentos, além de sugestões para atividades extraclasses.

Os PCN (1997) têm também como pressuposto que o aluno pode apreender a realidade na sua diversidade e nas múltiplas dimensões temporais. Destacam os compromissos e as atitudes de indivíduos, de grupos e de povos na construção e na reconstrução das sociedades, propondo questões locais e regionais.

Há também nos PCN uma forte ênfase na questão dos sujeitos históricos, colocando como objetivo da educação esta construção, valorizando o papel de cada um na construção da história de todos, possibilitando que a memória também possa ser um instrumento para 
esta construção, quando diz que "O sujeito histórico pode ser entendido, por sua vez, como sendo os agentes de ação social, sendo eles indivíduos, grupos ou classes sociais".

Para o ensino fundamental a LDB (1996, pág.17) em seu Artigo 22, estabelece que "a educação básica tem por finalidade desenvolver o educando, assegurar-lhe a formação comum indispensável para o exercício da cidadania e fornece-Ihe meios para progredir no trabalho e em estudos posteriores." (Lei no 9.394/96)

Esta lei vem reforçar a importância de um ensino de História que valoriza o senso crítico de seus alunos.

\section{A IMPORTÂNCIA DO ENSINO DE HISTÓRIA NO AMBIENTE ESCOLAR}

"Seja como for, a aula [de História] pode tornar-se um pensamento em formação que continua a se criar diante dos alunos, ou antes, com os alunos".

(Georges Snyders, 1995)

O ensino de História pode desempenhar um papel importante na configuração da identidade ao incorporar a reflexão sobre o indivíduo nas suas relações pessoais com o grupo de convívio, suas afetividades, sua participação no coletivo e suas atitudes de compromisso com classes, grupos sociais, culturais, valores e com gerações passadas e futuras.

De acordo com os PCN, o ensino de História é portador da possibilidade de levar o aluno a estabelecer relações e produzir reflexões sobre culturas, espacialidades e temporalidades variadas através da construção de noções que contemplem os seus valores e os de seu grupo, desenvolvendo para isto relações cognitivas que o levem a intervir na sociedade.

Para ensinar História a partir da experiência de vida do aluno faz-se necessária uma perspectiva teórico-metodológica que fale da vida das pessoas, as memórias e lembranças dos sujeitos de todos os segmentos sociais. É preciso dar voz às histórias desses sujeitos que sempre estiveram excluídos dos conteúdos ensinados.

O ensino de História pode também possibilitar ao aluno reconhecer a existência da história crítica e da história interiorizada e a viver conscientemente as especificidades de 
cada uma delas. $\mathrm{O}$ estudo de sociedades de outros tempos e lugares pode possibilitar a constituição da própria identidade coletiva na qual o cidadão comum está inserido, à medida que introduz o conhecimento sobre a dimensão do 'outro', de uma 'outra sociedade', 'outros valores e mitos', de diferentes momentos históricos.

Ensinar História requer do professor a habilidade de buscar sentido e significado para o conhecimento que ministra. E isso significa superar a mera transmissão de informações, já que essa não tem por finalidade o desenvolvimento intelectual, mas, ao contrário, deforma a capacidade de pensamento histórico do aluno e a possibilidade de consolidar habilidade de análise da própria realidade social.

No processo de aprendizagem de História, o professor é o principal responsável pela criação das situações de troca, de estímulos na construção de relações entre o estudado e o vivido, de integração com outras áreas de conhecimento, de possibilidade de acesso aos alunos a novas informações, de confronto de opiniões, de apoio ao estudante na recriação de suas explicações e de transformações de suas concepções históricas.

A seleção dos conteúdos faz parte de um conjunto formado pela preocupação com - saber escolar, com as capacidades e as habilidades e não pode ser trabalhada independentemente. Busca-se a coerência entre os objetivos da disciplina e os fundamentos historiográficos e pedagógicos.

Com isso, o aluno estará construindo um instrumental conceitual que permitirá a identificação das diferenças e de suas formas próprias de realização na História; estará também superando o egocentrismo e o individualismo na compreensão de caráter social da experiência humana. (SEE/RJ, 1994, p.77)

O ensino de História fornece aos seus alunos a capacidade de compreensão da construção do conhecimento histórico oferecendo habilidades e competências para o seu aprendizado.

Nesse sentido, os conteúdos ocupam papel central no processo de ensinoaprendizagem e sua seleção e escolha deve estar em consonância com as problemáticas sociais marcantes em cada momento histórico. Além disso, eles são concebidos não apenas como a organização dos fenômenos sociais historicamente situados na exposição de fatos e conceitos, mas abrangem também os procedimentos, os valores, as normas e as atitudes. 
A compreensão da disciplina História passa por uma compreensão de como a história é construída a partir das evidências do passado e essa construção é feita sempre distanciada do mesmo. A história não é o passado, mas a sua reconstrução a partir das evidências balizadas pelas compreensões possíveis e pelos interesses do momento da reconstrução.

A apreensão das noções de tempo histórico em suas diversidades e complexidades pode favorecer a formação do estudante como cidadão, fazendo-o aprender a discernir os limites e possibilidades de sua atuação na permanência ou na transformação da realidade histórica em que vive.

A aprendizagem de metodologias apropriadas para a construção do conhecimento histórico é essencial para que o aluno possa apropriar-se de um olhar consciente para sua própria sociedade e para si mesmo.

A possibilidade de o conhecimento histórico introduzir no espaço escolar as experiências vividas pelas pessoas comuns e trabalhar metodologicamente essas experiências por meio de documentos acumulados ao longo da vida, tornou-se possível graças às novas abordagens do pensamento historiográfico contemporâneo.

Este conhecimento tem possibilitado e fundamentado alternativas para métodos de ensino e recursos didáticos que valorizam o aluno como sujeito ativo no processo de aprendizagem. Uma das escolhas pedagógicas possíveis, nessa linha, é o trabalho favorecendo a construção, pelo aluno, de noções de diferença, semelhança, transformação e permanência.

O objetivo primeiro do conhecimento histórico é a compreensão dos processos e dos sujeitos históricos e o desenvolvimento das relações que se estabelecem entre os grupos humanos em diferentes tempos e espaços.

O estudo histórico desempenha um papel importante na medida em que contempla reflexões das representações construídas socialmente e das relações estabelecidas entre os indivíduos, os grupos, os povos e o mundo social em uma determinada época. Por isso este ensino pode proporcionar escolhas pedagógicas capazes de possibilitar ao aluno refletir sobre seus valores e suas práticas cotidianas e relacioná-las com problemáticas históricas inerentes ao seu grupo de convívio, à sua localidade, à sua região e à sociedade nacional e mundial. 
Perceber a complexidade das relações sociais presentes no cotidiano e na organização social mais ampla implica indagar qual lugar o indivíduo ocupa na trama da História e como são construídas as identidades pessoais e sociais em dimensão temporal.

O sujeito histórico que se configura na inter-relação complexa, duradoura e contraditória entre as identidades sociais e as pessoais, é o verdadeiro construtor da História. Assim, é necessário acentuar que a trama da História não é o resultado apenas da ação de figuras de destaque consagradas pelos interesses explicativos de grupos, mas sim a construção consciente e/ou inconsciente, paulatina e imperceptível de todos os agentes sociais, individuais ou coletivos.

A História, se concebida como processo, busca aprimorar o exercício da problematização da vida social como ponto de partida para a investigação produtiva e criativa, buscando identificar as relações sociais de grupos locais, regionais, nacionais e de outros povos; perceber as diferenças e semelhanças, os conflitos, as contradições e as solidariedades, igualdades e desigualdades existentes nas sociedades; comparar problemáticas atuais e de outros momentos; posicionar-se de forma crítica no seu presente e buscar as relações possíveis com o passado.

Zamboni (1993, pág.7) em artigo publicado sobre o papel da História na construção da identidade, afirma que:

[...] o objetivo fundamental da História no ensino fundamental, é situar o aluno no momento histórico em que vive [...]. O processo de construção da história de vida do aluno, de suas relações sociais, situado em contextos mais amplos, contribui para situá-lo historicamente em sua formação social, a fim de que seu crescimento social e afetivo desenvolva-Ihe o sentido de pertencer.

Em relação ao 3ำ e 4ำ ciclos os alunos já possuem habilidades para a construção de novos conceitos importantes para a sua formação.

Em uma de suas obras, o autor Urban (2009) articula a didática da História com a necessidade de levar o aluno a pensar historicamente. A consciência histórica é o objetivo central para que o aluno possa estabelecer conexões entre a história, a vida prática e a aprendizagem. Neste sentido, é necessário privilegiar as ideias históricas como ponto de partida para o ensino de História. 


\section{VALORIZANDO O COTIDIANO NO ENSINO DE HISTÓRIA}

"A vida cotidiana é o conjunto de atividades que caracterizam a reprodução dos homens singulares, os quais, por sua vez, criam a possibilidade de reprodução social".

(Agnes Heller, 1991)

A tarefa da disciplina História é fornecer ao estudante um senso de identidade que estimule e facilite sua cooperação com o outro: pessoas, nações, culturas diferentes. Trabalhando com a perspectiva da História do Cotidiano, a História se torna mais acessível às crianças e adolescentes do Ensino Fundamental.

Considerando o eixo temático 'história e cotidiano', a proposta do PCN é a de que, no primeiro ciclo, os alunos iniciem seus estudos históricos no presente, mediante a identificação das diferenças e das semelhanças existentes entre eles e suas famílias. Com os dados presentes, a proposta é que desenvolvam estudos do passado, identificando mudanças e permanências nas organizações familiares.

A introdução da História do Cotidiano como objeto de estudo escolar requer que se explorem as possibilidades inerentes do cotidiano, sem se limitar a constatar o "real" ou as motivações possíveis para alunos pouco sensibilizados com a História escolar mais tradicional. O cotidiano deve ser utilizado como objeto de estudo escolar pelas possibilidades que oferece de visualizar as transformações possíveis realizadas por homens comuns, ultrapassando a ideia de que a vida cotidiana é permeada de alienação.

Uma articulação dessa natureza requer concepção de cotidiano que não se apresente como mera motivação para o estudo do passado, selecionando as experiências amorosas de reis e rainhas ou o dia a dia de pessoas comuns ou famosas pautados por meras descrições curiosas e desligados do contexto social da existência desses indivíduos.

A História do Cotidiano tem-se convertido em uma das correntes assumidas por gerações de historiadores preocupados com uma história social capaz de redimensionar a visão política. Historiadores inspirados nos pressupostos marxistas, como Agnes Heller e E. Thompson, em suas reflexões reconheceram a necessidade dos estudos do cotidiano a fim de fazer emergirem as tensões sociais do dia a dia, as formas improvisadas de lutas, de resistência e de organizações diferentes das estabelecidas pelo poder institucional. 
O cotidiano pode ser utilizado como objeto de estudo escolar pelas possibilidades que oferece de visualizar as transformações realizadas por homens comuns, ultrapassando a ideia de que a vida cotidiana é repleta e permeada de alienação. Perceber o cotidiano como espaço privilegiado das transformações históricas também possibilita que os alunos percebam a si mesmos como sujeitos da História. A opção pela História do Cotidiano merece uma reflexão a respeito de seus pressupostos, para uma seleção de conteúdos coerentes com os objetivos centrais da disciplina.

O tema "cotidiano" tem grande importância na área de História, pois o cotidiano estabelece articulações com as grandes estruturas do poder políticas e econômicas. Seu estudo possibilita que as tensões do dia possam emergir, dando voz a atores sociais tradicionalmente excluídos e marginalizados, o que permite uma maior compreensão das estruturas sociais e suas transformações.

De acordo com Bittencourt (apud SILVA, s/d), a História do Cotidiano pode ser bastante útil em sala de aula, servindo como suporte fundamental para se reconsiderar o papel dos agentes sociais nas transformações históricas, levar à reflexão sobre a atuação dos sujeitos neste processo e rever concepções de tempo histórico.

Para a autora, a História do Cotidiano deve ser utilizada como ferramenta no ensino de História para romper a periodização clássica que consagra a ideia de evolução e de progresso, sequência de eventos vitoriosos de determinados sujeitos, o que acaba por fomentar a existência de hierarquias de valores entre as sociedades humanas.

Esta preocupação é também demonstrada por Le Goff (1997), para quem o cotidiano só tem valor histórico e científico no interior de uma análise de sistemas históricos que contribuem para explicar seu funcionamento, não se tratando de uma simples descrição de determinada sociedade numa época qualquer, tampouco de privilegiar histórias individuais.

Vários historiadores perceberam que o cotidiano não era apenas o lugar das pessoas comuns, mas também poderia ser considerado lugar de resistência e mudanças, exercendo papel central no acontecer histórico. O cotidiano estabelece articulações com as grandes estruturas de poder, políticas e econômicas. Seu estudo possibilita que as tensões e lutas do dia a dia possam emergir, dando voz a atores tradicionalmente excluídos e 
marginalizados, o que permitiria uma maior compreensão das estruturas sociais e suas transformações.

O cotidiano está relacionado com a possibilidade de que os alunos possam perceber como suas vidas fazem parte da História como um todo. Nesse sentido, de acordo com as expectativas de aprendizagem, é necessário "perceber criticamente os vínculos entre história de vida e história". A percepção é crítica e essencial para perceber não apenas essa relação, mas entender os processos que estabeleceram as articulações, entendendo sua produção social.

O ponto de partida para perceber esse vínculo é "analisar as relações entre história de vida e história, compreendendo-se como sujeito da história". As expectativas estabelecem as articulações entre a vida dos alunos (experiência) e a compreensão de contextos históricos diversos (perspectiva histórica). O eixo cotidiano pode ser importante nesse sentido.

O tema cotidiano tem abrangência inusitada, colocando o homem no centro do acontecer histórico, como aponta Agnes Heller (2008, p.17):

A vida cotidiana é a vida do homem inteiro; ou seja, o homem participa na vida cotidiana com todos os aspectos de sua individualidade, de sua personalidade. Nela, colocam-se 'em funcionamento' todos os seus sentidos, todas as suas capacidades intelectuais, suas habilidades, seus sentimentos, paixões, idéias, ideologias.

De acordo com Duarte (1993) baseado em Heller, "as atividades cotidianas do indivíduo referem-se ao conjunto de atividades que caracterizam a representação de cada indivíduo a partir da reprodução da sociedade".

Nessa ideia insere-se o conceito, que se apresenta na linguagem e nos costumes. Outro conceito importante refere-se à formação de uma relação consciente do indivíduo com sua vida cotidiana.

Nesse sentido, o cotidiano não pode ser entendido isoladamente. Aspectos cotidianos e não cotidianos se interpenetram na realidade social. O objetivo não é tratar de temas da vida cotidiana de forma isolada, mas articulados aos processos históricos gerais. 
Nas relações entre cotidiano e história, é necessário ter cuidado com a abordagem do lado "pitoresco" da História. É preciso tratar do cotidiano em sua íntima relação com as questões culturais, econômicas, sociais e políticas de cada época e sociedade.

O cotidiano não é apenas a simples repetição do dia a dia de pessoas comuns. Ele constitui a instância onde as relações sociais se realizam de forma concreta; a dimensão na qual as práticas sociais assumem corpo e efeito dando formas aos interesses em jogo.

\section{A INTERRELAÇÃO ENTRE MEMÓRIA E O ENSINO DE HISTÓRIA}

"A memória é um elemento essencial do que se costuma chamar identidade individual e coletiva"

(Jacques Le Goff, 2007)

O ensino de História possui objetivos específicos, sendo um dos mais relevantes, o que se relaciona à constituição da noção de identidade. Assim, é primordial que o ensino de História estabeleça relações entre identidades individuais, sociais e coletivas, entre as quais as que se constituem como nacionais.

Dentro dessa perspectiva, o ensino de História tende a desempenhar um papel mais relevante na formação da cidadania, envolvendo a reflexão sobre a atuação do indivíduo em suas relações pessoais com o grupo de convívio, suas afetividades e sua participação no coletivo.

Conforme as Orientações Curriculares para o Ensino Médio é importante a introdução do debate em sala de aula para que se compreenda o papel da memória na vida da população, dos vínculos que cada geração estabelece com outras gerações, das raízes culturais e históricas que caracterizam a sociedade humana.

A História, como memória, também é uma representação do passado, porém suas características a diferenciam, às vezes provocando um grave afastamento das duas memória e História.

A distinção entre memória e história, portanto, existe no próprio meio em que ambas se propagam: a memória se propaga e se corporifica no mundo da via; a História tem seu habitat na historiografia. 
Um compromisso fundamental da história encontra-se na sua relação com memória. É necessário chamar a atenção dos alunos para os usos ideológicos a que a memória histórica está sujeita que muitas vezes constituem "lugares de memória", estabelecidos pela sociedade e pelos poderes constituídos, que escolhem o que deve ser preservado e relembrado e o que deve ser silenciado e "esquecido".

Enfatiza-se também a riqueza que o conceito de memória vem adquirindo no âmbito da história. Evidencia-se, por exemplo, que os lugares da memória são criações da sociedade contemporânea para impor determinada memória, que a concepção de memória nacional ou identidade regional constitui formas de violência simbólica que silenciam e uniformizam a pluralidade de memórias associadas aos diversos grupos sociais.

Evidencia-se também o estudo da memória enquanto prática de representação social e, portanto, para o estudo das formas de regaste de memórias coletivas durante tempo esquecidas no espaço público pela memória oficial.

A 'Memória', no se sentido primeiro da expressão, é a presença do passado. A memória é uma construção que acarreta de fato uma representação seletiva do passado, que nunca é somente aquela do indivíduo, mas de um indivíduo inserido num contexto familiar, social e nacional.

Conforme Peter Burke (2000), os historiadores se interessam ou precisam se interessa pela memória, considerando dois pontos de vista: como fonte histórica e como fenômeno histórico.

Sob o primeiro aspecto, além de estudarem a memória como fonte para a história, os historiadores devem elaborar uma crítica da reminiscência, nos moldes da operação de análise dos documentos históricos.

No que tange ao segundo aspecto, os historiadores devem estar interessados no que o autor denomina "história social do lembrar". Partindo-se da premissa de que a memória social, como a individual, é seletiva, faz-se necessário identificar os princípios de seleção e observar como os mesmo variam de lugar para lugar, ou de um grupo para o outro e como se transformam na passagem do tempo.

Para Michael Pollak, 
A memória é um elemento constituinte do sentimento de identidade, tanto individual quanto coletivo, na medida em que ela é também um fator extremamente importante do sentimento de continuidade e de coerência de uma pessoa ou de um grupo em sua reconstrução de si.

Pollak, Buker e Le Goff reforçam a importância do conhecimento histórico para uma maior compreensão das identidades individuais e coletivas.

De acordo com Peter Buker (2000, pág.70), os indivíduos identificam-se com os acontecimentos públicos relevantes para o seu grupo: "Lembram muito que não viveram diretamente. Um artigo de noticiário, por exemplo, às vezes se torna parte da vida de uma pessoa. Daí pode-se descrever a memória como uma reconstrução do passado".

Conforme Jacques Le Goff (1994) deve haver um vínculo entre a história e a memória:

A memória, onde cresce a história, que por sua vez a alimenta, procura salvar o passado para servir o presente e o futuro. Devemos trabalhar de forma que a memória coletiva sirva para libertação e não para a servidão dos homens (pág.477).

Resgatar memórias por meios dos monumentos, histórias de seus moradores, e pelos próprios acontecimentos locais. Para Circe Bittencourt (2004, pág.168), "a memória é, sem dúvida, aspecto relevante na configuração de uma história local tanto para historiadores quanto para o ensino".

A história, para Le Goff (ibidem) "consiste na escolha e construção de um objeto, operação que pode dar-se a partir de evocações de lembranças", e exige, na análise das memórias, um rigor metodológico na crítica e na confrontação com outros registros e testemunhos.

Conforme Montenegro (2001)

A memória tem como característica fundante o processo relativo que a realidade provoca no sujeito. Ela se forma e opera a partir da reação, dos efeitos, do impacto sobre o grupo ou o indivíduo, formando um imaginário que se constituiu em uma referência permanente de futuro. (pág.19)

Estes autores acima citados demonstram ser fundamental a valorização da memória como forma de recuperar a história de vida individual e coletiva. 
A questão da memória impõe-se por ser base da identidade, e é pela memória que se chega á história local. Além da memória das pessoas, escrita ou recuperada pela oralidade, existem "lugares da memória", expressos por monumentos, praças, edifícios públicos ou privados, mas preservados como patrimônio histórico. Os vestígios do passado de todo e qualquer lugar, de pessoas e de coisas, de paisagens naturais ou construídas tornam-se objeto de estudo.

\section{CONHECENDO A HISTÓRIA LOCAL E DESENVOLVENDO SEU ENSINO}

"Talvez mostrando as pessoas eu possa ser mais fiel ao lugar e à época"

(Aldir Blanc, 1996)

A História Local é entendida como uma modalidade de estudos históricos que contribuiu para a construção dos processos interpretativos sobre as formas como os atores sociais se constituem historicamente em seus modos de viver, situados em espaços que são socialmente construídos e repensados pelo poder político e econômico na forma estrutural de "bairros e cidades".

A História Local é a história que trata de assuntos referentes a uma determinada região, município, cidade, distrito. Apesar de estar relacionada a uma história global, a história local se caracteriza pela valorização dos particulares, das diversidades; ela é um ponto de partida para a formação de uma identidade regional.

Ela tem sido compreendida como "história do lugar". Nesse aspecto, a localidade tem-se tornado objeto de investigação e ponto de partida para a produção de conhecimentos sobre o passado.

É a partir do local que o aluno começa a construir sua identidade e a se tornar membro ativo da sociedade civil, no sentido de que faz prevalecer seu direito de acesso aos bens culturais, sendo eles materiais ou não materiais.

A História Local geralmente se liga à História do Cotidiano ao fazer as pessoas comuns participantes de uma história aparentemente desprovida de importância e estabelecer relações entre os grupos sociais de condições diversas que participaram de entrecruzamentos de histórias, tanto no presente quanto no passado. 
O local é o espaço primeiro da atuação do homem, por isso, o ensino de história local precisa configurar também essa proposição de oportunizar a reflexão permanente acerca das ações do que ali vivem como sujeitos históricos e cidadãos.

Assim sendo, ensino de História Local pode configurar-se como um espaço que o local e o presente são referentes para o processo de construção de identidade.

Um cuidado que se deve ter com o estudo da história local é a identificação do conceito de espaço. É comum falar em História Local como a história do entorno, do mais próximo, do bairro ou da cidade. Cada lugar tem suas especificidades e precisa ser entendido por meio da série de elementos que o compõem e de suas funções.

Os Parâmetros Curriculares Nacionais de História, para o 1ํ e 2을 Ciclos, destacam a importância de conhecer as características dos grupos sociais de seu convívio diário, para que ampliem estudos sobre o viver de outros grupos da sua localidade presente, identificando as semelhanças e as diferenças existentes entre os grupos sociais e seus costumes.

Já os Parâmetros Curriculares Nacionais para o Ensino Fundamental (1998), em suas séries iniciais valoriza o estudo da localidade:

A preocupação com os estudos de história local é a de que os alunos ampliem a capacidade de observar o seu entorno para compreensão de relações sociais e econômicas existentes no seu próprio tempo e reconheçam a presença de outros tempos no seu dia-a-dia. (pág.40)

Os Parâmetros Curriculares Nacionais para o Ensino Médio, na área de história, recentemente divulgados (1997 e 1998), foram construídos a partir de uma ótica que devem ser tomados como referência para trabalhar a experiência e os contextos mais amplos:

O ensino e aprendizagem de História estão voltados, inicialmente, para atividades em que os alunos possam compreender as semelhanças e as diferenças, as permanências e as transformações do modo de vida social, cultural e econômico de sua localidade, no presente e no passado, mediante a leitura de diferentes obras humanas. (Brasil/MEC/SEF, pág.49)

De acordo com o PCN: 
Os estudos da história local conduzem aos estudos de diferentes modos de viver no presente em outros tempos, que existem ou que existiram no mesmo espaço. Nesse sentido, a proposta os estudos históricos é de favorecer o desenvolvimento das capacidades de diferenciação e identificação, com a intenção de expor as permanências de costumes e relações sociais, as mudanças, as diferenças e as semelhanças das vivências coletivas, sem julgar grupos sociais. Classificando-os como mais evoluídos ou atrasados. (Brasil/MEC/SEF, pág.52)

A História Local foi valorizada também como estudo do meio, ou seja, "como recurso pedagógico privilegiado [...] que possibilita aos estudantes adquirirem, progressivamente, o olhar indagador sobre o mundo de que fazem parte", segundo os Parâmetros Curriculares Nacionais, (1998, pág. 9).

Estes parâmetros contribuem para o desenvolvimento de metodologias e estratégias para uma maior compreensão da História Local.

A História Local permite ao educando perceber-se como sendo parte integrante da história, não simples espectador do ensino desta, mas objeto e sujeito, construtor de fatos e acontecimentos que não lineares, mas permeados de descontinuidades próprias do processo histórico.

Enquanto estratégia de aprendizagem, a História Local, pode garantir o domínio do conhecimento histórico. Seu trabalho no ensino possibilita a construção de uma História mais plural, que não silencie a multiplicidade das realidades.

Para ensinar História a partir da experiência de vida do aluno, é necessária uma perspectiva teórico-metodológica que fale da vida das pessoas, das memórias e lembranças dos sujeitos de todos os segmentos sociais. É preciso dar voz á histórias desses sujeitos que sempre estiveram excluídos dos conteúdos ensinados.

O trabalho com a História Local no ensino da História facilita, também, a construção de problematização, a apresentação de várias histórias lidas com base em distintos sujeitos da história, bem como de histórias que foram silenciadas, isto é, que não foram institucionalizadas sob a forma de conhecimento histórico. Ademais, esse trabalho pode favorecer a recuperação de experiências individuais e coletivas do aluno, fazendo-o vê-las como constitutivas de uma realidade histórica mais ampla e produzindo um conhecimento que, ao ser analisado e retrabalhado, contribui para a construção de sua consciência histórica. 
Como elemento constitutivo da transposição didática do saber histórico para o saber escolar, a História Local pode ser vista como estratégia pedagógica. Trata-se de uma forma de abordar a aprendizagem, a construção e a compreensão do conhecimento histórico com proposições que podem ser articuladas com os interesses do aluno, suas aproximações cognitivas, suas experiências culturais e com a possibilidade de desenvolver atividades diretamente vinculadas à vida cotidiana.

De acordo com Neves (1997, pág.7), "[...] a construção do conhecimento a partir da vivência, portanto, do local e do presente, é a melhor forma de superar a falsa dicotomia entre a produção e a transmissão, entre pesquisa e o ensino/divulgação, enfim, entre o saber e o fazer".

A partir destas novas perspectivas historiográficas encontram-se também as preocupações da utilização da História Local no ensino de História. Para Proença (1990, pág.139): "Assiste-se presentemente ao desenvolvimento de uma História Local que visa tirar partido das novas metodologias e cujos temas poderão ter um aproveitamento didático motivador e estimulante".

Segundo Giroux e Simon (1994, pág.99), são abordagens desse tipo que apresentam um ganho pedagógico para os estudantes ao tornar disponíveis "aquelas narrativas, histórias locais e memórias que foram excluídas e marginalizadas nas interpretações dominantes da história".

O novo interesse da História Local volta-se para uma abordagem social que procura reconstruir as condições de vida dos diversos grupos sociais de uma determinada localidade. Como afirma Goubert (1998, pág.73.): “A volta à História Local origina-se de um novo interesse pela História Social - ou seja, a história da sociedade como um todo".

Para Neves, Proença, Giroux, Simon e Goubert, é relevante que o ensino de História forneça estratégias teórico-metodológicas para o desenvolvimento em sala de aula que valorizem a história de vida de seus alunos.

É preciso destacar que a utilização da história local como estratégia pedagógica é uma maneira interessante e importante para articular os temas trabalhados em sala de aula. O papel do ensino de História na configuração identitária dos alunos é um dos aspectos relevantes para considerar ao proporem-se estudos da história local. 
Para efetivar o estudo do local, a proposta fundamenta-se na história do cotidiano e apropria-se de seus métodos, como objetivo de inserir as ações de pessoas comuns na constituição histórica e não exclusivamente as ações de políticos e das elites sociais.

A História Local no ensino não deve ser tratada apenas como um conteúdo a ser ensinado, mas constituir-se em uma estratégia pedagógica que trate metodologicamente os conteúdos a partir da realidade local. Ela deve ser escrita a partir das novas fontes: a identificação das edificações antigas, do traçado das ruas, da memória dos mais antigos, das mudanças do cotidiano urbano que só podem ser observadas pelos olhares mais atentos ou orientados.

Seu estudo constitui o ponto de partida da aprendizagem histórica, uma vez que permite a abordagem dos contextos mais próximos em que se inserem as relações sociais entre os professores, os estudantes e o meio. Nessa perspectiva, o ensino-aprendizagem da história local configura-se como um espaço-tempo de reflexão crítica acerca da realidade social e, sobretudo, referência para o processo de construção das identidades destes sujeitos e de seus grupos de pertença.

A história do "lugar" como objeto de estudo ganha, necessariamente, contornos temporais e espaciais. Não se trata, portanto, ao se proporem conteúdos escolares da história local, de entendê-los apenas na história do presente ou de determinado passado, mas de procurar identificar a dinâmica das transformações do espaço e articular esse processo às relações externas, a outros "lugares".

\section{CONCLUSÃO}

Este trabalho demonstrou ser fundamental que o ensino de História incorpore em seu conteúdo metodologias que possam inserir em sala de aula o cotidiano dos alunos sobre a importância de uma História Local que valorize sua memória.

Os autores citados reforçam a valorização dessas temáticas que favoreçam uma compreensão dialógica sobre o papel do ensino de História e sua reconstrução das identidades históricas coletivas e individuais. 
Devemos valorizar a memória dos sujeitos históricos que constroem suas histórias diariamente, pois o ensino de História Local permite que possamos dar vozes àqueles autores que estiveram marginalizados pela História Oficial.

O ensino de História tem como principal pressuposto formar cidadãos que possam ser críticos com a realidade na qual estão inseridos, devido ao fato de que seus conceitos e conteúdos possam fazer com que os alunos debatam sobre o que está acontecendo não somente sobre o passado, mas também sobre o presente.

É necessário que o ambiente escolar forneça condições para que os professores possam desenvolver novas metodologias para que incorporem os conteúdos de história local em seus componentes curriculares, pois poderão inserir seus alunos como cidadãos críticos no ambiente em que vivem.

Como educadores, temos a responsabilidade de ensinar uma História que faça parte do dia a dia do aluno, pois somente assim o ensino de História para eles terá outro significado e sua aprendizagem será reconhecida por todos.

\section{REFERÊNCIAS}

ALMEIDA FILHO, Orlando José de. OMURO, Selma de Araujo Torres. História a Ser Ensinada: Algumas Reflexões em Torno da História Local. (s/d) In: www.unifia.edu.br. Julho de 2012.

BARBOSA, Vilma de Lurdes. Ensino de História Local: Redescobrindo Sentidos. Saeculum Revista de História. João Pessoa: jul/dez, 2006.

BITTENCOURT, Circe Maria Fernandes. Ensino de História: Fundamentos e Métodos. Editora Cortez: São Paulo, 2009.

(Org.). O Saber Histórico na Sala de Aula. Editora Contexto: São Paulo, 2009. (Repensando o Ensino).

BRASIL/MEC/SEF. Coleção explorando o ensino de história: Ensino Fundamental. Volume 21, 2010.

BRASIL/MEC/SEF. Parâmetros Curriculares Nacionais, 1997. 
BRASIL, Parâmetros Curriculares Nacionais: Ensino Fundamental 1ํ e 2 Ciclos - História. Brasília: MEC/SEF, 1997.

BRASIL, Parâmetros Curriculares Nacionais: Ensino Fundamental 3ㅇ e 4ํ Ciclos - História. Brasília: MEC/SEF, 1998.

BRASIL, Lei no 9.394/96 - Diretrizes e Bases da Educação Nacional. Brasília: Ministério da Educação, 20 dez. 1996, Artigo 22.

BRASIL, Orientações Curriculares Para O Ensino Médio: Conhecimentos de História. Brasília: Ministério da Educação, Secretaria de Educação Básica, 2006.

BURKE, Peter. "História Como Memória Social". In: Variedades de História Cultural. Rio de Janeiro: Civilização Brasileira, 2000

Caderno de Orientações Didáticas para EJA. História: Etapas Complementar e Final. São Paulo: SME/DOT, 2010.

DUARTE, Newton. A Individualidade Para Si - Contribuição e uma Teoria Histórico-Social da Formação do Indivíduo. Campinas, Autores Associados, 1993.

FONSECA, Selva Guimarães. Didática e Prática de Ensino de História: Experiências, Reflexões e Aprendizados. Editora Papirus: São Paulo, 2003. Coleção Magistério: Formação e Trabalho.

GADDIS, John Lewis. Paisagens da História. Como os Historiadores Mapeiam o Passado. Rio de Janeiro: Campus, 2003.

GASPARELLO, Arlette Medeiros. MAGALHÃES, Marcelo de Souza. MONTEIRO, Ana Maria F. C. (orgs). Ensino de História: Sujeitos, Saberes e Práticas. Editora Mauad: Rio de Janeiro, 2009.

GIROUX, Henry \& SIMOM, Roger. Cultura Popular e Pedagogia Crítica: A Vida Cotidiana Como Base Para O Conhecimento Curricular. In: MOREIRA, Antônio F. B. e Silva, Tomaz Tadeu (orgs.). Currículo, Cultura e Sociedade. São Paulo: Cortez, 1994.

GOUBERT, Pierre. História Local. Revista Arrabaldes - Por Uma História Democrática. Rio de Janeiro. n. 1, maio/ago, 1988.

HELLER, Agnes. O Cotidiano e a História. São Paulo: Paz e Terra 2008.

HORN, Geraldo Balduíno. GERMINARI, Geyso Dongley. O Ensino de História e seu Currículo: Teoria e Método. Editora Vozes: Rio de Janeiro, 2010. 
KARNAL, Leonardo (org.). História na Sala de Aula: Conceitos, Práticas e Propostas. Editora Contexto: São Paulo, 2010.

LE GOFF, Jacques. Memória. In: História e Memória. Campinas: Ed. UNICAMP, 1994.

MONTENEGRO, Ana Maria da Costa. Ensino de História: Das Dificuldades e Possibilidades de um Fazer. In. DAIVES, N. (org.) Para Além dos Conteúdos no Ensino de História. Niterói: Eduff, 2000.

MORALES, Elisa Vermelho: História do cotidiano e ensino de História. (s/d) In: www.uel.br. Acessado em: Julho de 2012.

MOREIRA, Raimundo Nonato Pereira. História e Memória: Algumas Observações. (s/d) In: www.fja.edu.br/. Acessado em: Agosto de 2012.

NEVES, Joana. História Local e Construção da Identidade Social. Saeculum - Revista de História. João Pessoa: Departamento de História da Universidade Federal da Paraíba, n. 3, jan./dez. 1997.

NORONHA, Isabelle de Luna Alencar. Livro Didático e Ensino de História Local no Ensino Fundamental: Associação Nacional de História - ANPUH XXIV. Simpósio Nacional de História, 2007.

POLLAK, Michael. Memória e Identidade Social. Estudos Históricos, v.5, n.10, Rio de Janeiro: CP/DOC FGV, 1992.

PROENÇA, Maria Cândida. Ensinar/Aprender História. Lisboa: Horizonte, 1990.

RIO DE JANEIRO (Estado). Secretaria de Educação. Plano Básico de Estudos: Anos Iniciais da Escola Básica. Rio de Janeiro: COGP/Coeb, 1994.

SANTOS, Luciana Souza. O cotidiano e o não cotidiano na educação. Artigo de mestrado. (s/d) In: www.uninove.br Acessado em: Novembro de 2012

SCHMIDT, Maria Auxiliadora. CAINELLI, Marlene. Ensinar História. 2ำ ed. São Paulo: Editora Scipione, 2009. Coleção Pensamento e Ação em Sala de aula.

SILVA, Marcos. O Ensino de História no Curso Fundamental. (s/d) In: $\underline{\text { www.valesilva.com.br }}$ Acessado em: Novembro de 2012.

THEOBALD, Henrique Rodolfo. Fundamentos e Metodologia do Ensino de História. Editora Fael: Curitiba, 2010. 
URBAN, A. C. Didática da História: Percursos de um Código Disciplinar no Brasil e na Espanha. Tese (Doutorado em Educação) - Universidade Federal do Paraná, Curitiba, 2009.

ZAMBONI, Ernesta. O Ensino de História e a Construção da Identidade. História-Série Argumento. São Paulo: SEE/Cenp, 1993. 